\title{
MODELAGEM TERMODINÂMICA DE SISTEMAS ASSOCIATIVOS: AVALIAÇÃO DA EXTENSÃO DA AUTO- ASSOCIAÇÃO DE ÁLCOOIS EM MISTURAS COM COMPOSTOS INERTES POR MEIO DE DINÂMICA MOLECULAR
}

\author{
H. M. MARTINS ${ }^{1}$, R. R. ROMEIRO ${ }^{1}$, P. A. PESSÔA FILHO ${ }^{1}$ \\ ${ }^{1}$ Universidade de São Paulo, Departamento de Engenharia Química \\ E-mail para contato: pedro.pessoa@poli.usp.br
}

\begin{abstract}
RESUMO - Este trabalho tem por objetivo estudar, do ponto de vista de modelagem termodinâmica, a auto-associação de um álcool em mistura com componentes inertes. Neste contexto, entende-se auto-associação como a capacidade das moléculas de um composto em formar ligações de hidrogênio com outras moléculas do mesmo composto. A extensão da auto-associação tal como determinada experimentalmente por espectroscopia de infravermelho por transformada de Fourier (FT-IR) é comparada com dados gerados por meio de simulações de dinâmica molecular. Espera-se que os resultados da pesquisa ajudem a elucidar o comportamento de modelos e simulações aplicados a sistemas contendo compostos que formam ligações de hidrogênio.
\end{abstract}

\section{INTRODUÇÃO}

A maioria das operações de separação presentes na indústria química envolve o contato de duas fases líquidas, ou de uma fase líquida e uma fase vapor. No desenvolvimento de qualquer dessas operações, é necessário conhecer o estado de equilíbrio do sistema, ou seja, dado um certo conjunto de restrições (que podem envolver a definição da temperatura, pressão, composição de fases ou restrições ligadas a balanços de massa e energia), é necessário calcular qual será o estado de equilíbrio atingido. Para essa finalidade, é necessário utilizar modelos termodinâmicos, como modelos de energia de Gibbs excedente (para a fase líquida) e equações volumétricas de estado (para a fase vapor e, eventualmente, também para a fase líquida).

Um conjunto de misturas para as quais o desenvolvimento de modelos é bastante complexo é constituído pelas misturas contendo compostos auto-associativos. Entende-se por compostos auto-associativos aqueles cujas moléculas são capazes de formar ligações de hidrogênio com outras moléculas do mesmo composto, como a água, os álcoois e os ácidos carboxílicos (Prausnitz et al., 1999). Essas ligações são suficientemente estáveis para que se possa considerá-las semelhantes, do ponto de vista de modelagem, às ligações covalentes. Misturas contendo compostos associativos, como misturas de álcoois com hidrocarbonetos, exibem comportamento extremamente não ideal, devido justamente às fortes interações por ligações de hidrogênio presentes (Voutsas et al., 2007). Tais misturas podem ser descritas 
pelo modelo de associação UNIQUAC, o qual assume que monômeros, dímeros e oligômeros possuem os mesmos parâmetros energéticos de interação com o solvente (Asprion et al., 2001). O modelo de associação UNIQUAC assume que o fluido auto-associativo é uma mistura de "clusters" em equilíbrio químico com as formas monoméricas, e que o comportamento não ideal da fase líquida em estudo é descrito por meio da energia de Gibbs do sistema.

Nesse trabalho, apresenta-se uma avaliação sobre a compatibilidade dos resultados de dinâmica molecular e os valores de extensão da auto-associação experimentalmente determinados por meio de FT-IR, conforme Asprion et al. (2001). Para essa finalidade, foram estudadas misturas binárias envolvendo um álcool e um hidrocarboneto inerte (do ponto de vista de ligações de hidrogênio, como um alcano), compreendendo os sistemas experimentalmente estudados (Asprion et al., 2001). O estudo dessas misturas é relevante pois seus componentes apresentam propriedades associativas bastante distintas, o que interfere fortemente no comportamento da mistura: desvios positivos da lei de Raoult são comuns nesse tipo de sistemas, e a separação de duas fases líquidas em baixas temperaturas é comum.

Embora sistemas associativos sejam rotineiramente estudados em simulações de dinâmica molecular, o estudo específico do número médio de ligações, e sua comparação com resultados experimentais e/ou calculados por meio de outras teorias não é trivial. Espera-se que a realização deste trabalho leve a uma melhor compreensão dos termos importantes em modelos que levem em conta a formação de ligações de hidrogênio.

\section{OBJETIVOS}

Este projeto tem como objetivo comparar os resultados de simulações de dinâmica molecular e da equação volumétrica de estado PC-SAFT com os resultados experimentais sobre a extensão das ligações de hidrogênio em sistemas contendo compostos autoassociativos e inertes.

\section{FUNDAMENTAÇÃO TEÓRICA}

\subsection{Dinâmica Molecular}

Dinâmica molecular é o termo utilizado para descrever a solução das equações de movimento clássicas (equações de Newton) para um arranjo de moléculas (Allen e Tildesley, 1987).

As simulações de dinâmica molecular são um dos métodos disponíveis para a geração de modelos representativos de sistemas reais, que podem encontrar-se em equilíbrio ou fora dele, além de serem apropriadas à análise de eventos dinâmicos que ocorrem em nível molecular. Durante as simulações, as equações de movimento para $N$ átomos interagindo entre si são resolvidas simultaneamente. As forças que agem em cada átomo são obtidas por meio da derivação da função potencial $V\left(r_{1}, r_{2}, \ldots, r_{N}\right)$, que pode incluir termos como o potencial de Lennard-Jones e o potencial relativo às forças coulômbicas. 
As coordenadas das partículas simuladas como uma função do tempo representam a trajetória do sistema. Tal trajetória, quando o sistema se encontra em equilíbrio, é capaz de fornecer algumas de suas propriedades macroscópicas.

\section{MATERIAIS E MÉTODOS}

Para a realização das simulações, foi utilizado o software GROMACS, uma ferramenta destinada à execução de simulações de dinâmica molecular.

O primeiro dos passos para a realização das simulações de dinâmica molecular foi determinar o número de moléculas de cada composto presentes em cada uma das caixas de simulação. Para efeitos de comparação, a fração entre o número de moléculas de álcool e hexano deveria respeitar as frações molares dos sistemas analisados experimentalmente por Asprion et al. (2001). Além disso, foi estabelecido a priori que cada um dos sistemas simulados deveria apresentar 20000 átomos a fim de se obter uma simulação capaz de gerar resultados que pudessem ser estendidos da escala nanométrica para a escala experimental laboratorial.

Com o auxílio do software Avogadro, as moléculas de etanol e hexano foram construídas utilizando-se um campo de forças geral AMBER (GAFF). Como resultado, obteve-se um arquivo com as coordenadas de cada um dos átomos para ambas as moléculas.

Posteriormente, foi necessário gerar topologias para cada uma das moléculas. Os parâmetros relacionados aos átomos, às ligações, às interações entre pares de átomos, aos ângulos de ligação, e aos diedros foram obtidos diretamente do campo de forças OPLS-AA, desenvolvido por Jorgensen et al. (1996).

Uma vez conhecidos os números de moléculas de etanol e hexano em cada um dos sistemas a ser simulado bem como o tamanho da caixa de simulação e as coordenadas dos átomos de cada molécula, um código computacional foi redigido na linguagem $\mathrm{C}$ com o intuito de se inserir a quantidade adequada de moléculas nas caixas de simulação.

A metodologia aplicada às simulações consistiu de quatro etapas sequenciais, sendo elas: minimização, equilibração NVT, equilibração NPT e simulação de dinâmica molecular. Para cada uma das etapas utilizaram-se métodos específicos para controlar a temperatura (termostatos) e a pressão (barostatos) dos sistemas. Também foram levadas em consideração as interações dispersivas e eletrostáticas entre as partículas através de algoritmos de cálculo de potenciais. Além disso, com o intuito de se obter ao menos 200 ns de simulação molecular, o passo de integração adotado para a simulação foi de $10^{-3}$ ps.

Para a análise do número de ligações de hidrogênio, foi utilizada a função do GROMACS gmx hbond. As ligações são determinadas baseadas em cut-offs para o ângulo e a distância entre doadores e aceptores. 
Foram simulados os seguintes sistemas propostos inicialmente, sendo eles aqueles nos quais a fração molar percentual de etanol em hexano era igual a: 16,030;12,800;10,020; 6,$400 ; 3,168 ; 1,600 ; 1,196 ; 0,800 ; 0,597 ; 0,402 ; 0,299 ; 0,200 ; 0,101$.

\section{RESULTADOS PARCIAIS}

A Tabela 1 resume os resultados obtidos para os sistemas simulados contendo etanol em hexano. Nessa Tabela, $X_{i}$ é a fração molar percentual de etanol na mistura. As colunas "Experimental" e "Computacional" exibem a fração percentual de grupos não ligados da moléculas de etanol identificada por cada um dos métodos. Ou seja, assume-se que cada molécula de etanol possui dois sítios que possibilitam a formação de ligações de hidrogênio com outras moléculas de etanol. Sabendo quantas ligações de hidrogênio existem em um dado volume para uma mistura de uma composição específica, é possível determinar a fração de grupos ligados e não ligados.

Tabela 1 -Frações percentuais de grupos não ligados para misturas de composição Xi de etanol em hexano à $298,15 \mathrm{~K}$ e 1 bar pelos métodos experimental e computacional.

\begin{tabular}{|c|c|c|}
\hline $\mathrm{Xi}(\%)$ & Computacional (\%) & Experimental (\%) \\
\hline 16,030 & 55,9 & 64,6 \\
\hline 12,800 & 56,3 & 64,6 \\
\hline 10,020 & 57,2 & 66,0 \\
\hline 6,400 & 58,9 & 68,8 \\
\hline 3,168 & 68,3 & 73,9 \\
\hline 1,600 & 80,8 & 82,3 \\
\hline 1,196 & 93,0 & 86,3 \\
\hline 0,800 & 91,7 & 90,5 \\
\hline 0,597 & 93,3 & 94,1 \\
\hline 0,402 & 97,0 & 96,1 \\
\hline 0,299 & 99,9 & 98,0 \\
\hline 0,200 & 100,0 & 98,4 \\
\hline 0,101 & 100,0 & 98,8 \\
\hline
\end{tabular}

A Figura 1 foi produzida através do visualizador de dinâmica molecular do GROMACS. A caixa à esquerda exibe a configuração final do sistema. Já a caixa da direita mostra apenas os átomos de oxigênio do sistema. Como os átomos de oxigênio só estão presentes nas moléculas de etanol, a sua aglomeração leva a conclusão de que as moléculas de etanol interagem entre si por meio de ligações de hidrogênio. 
Figura 1 - Estado final da simulação da mistura de etanol e hexano 16,030\%.

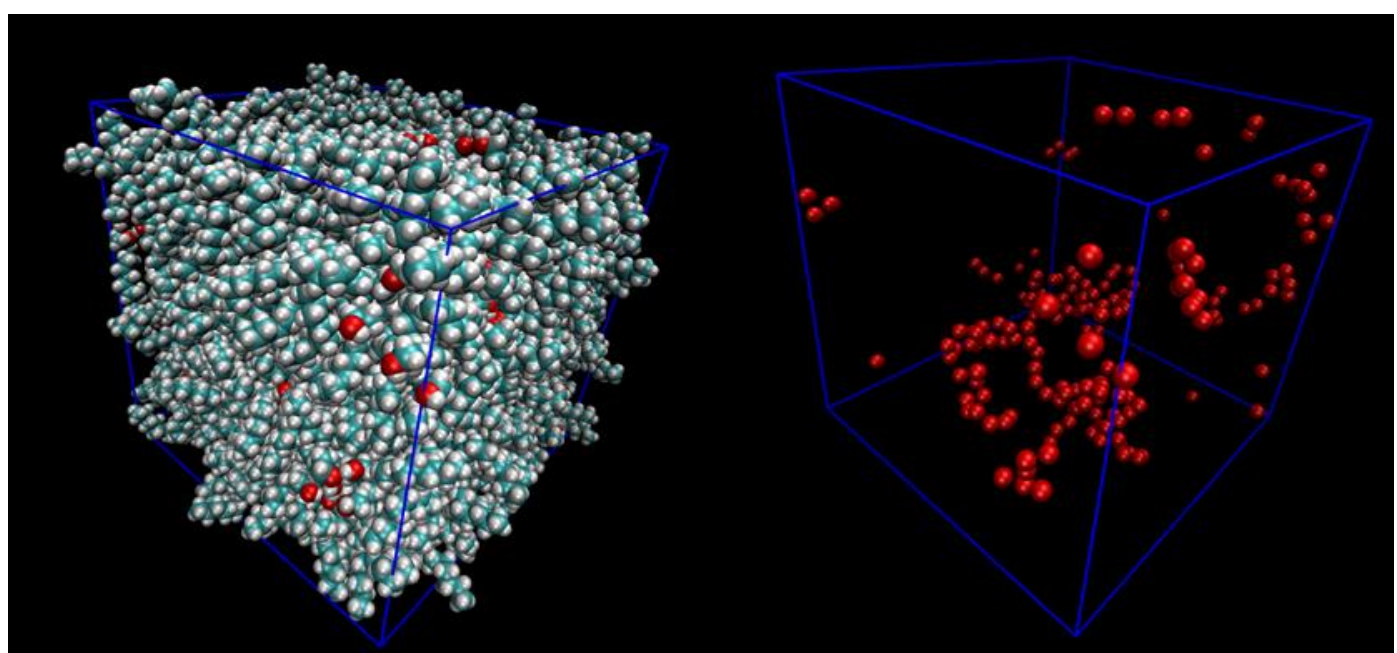

\section{CONCLUSÕES}

De modo geral, os resultados mostraram que as simulações de dinâmica molecular reproduzem adequadamente a extensão da auto-associação determinada por FT-IR.

\section{REFERÊNCIAS}

Allen, M. P., Tildesley, D. J. Computer Simulation of Liquids

Asprion, N., Hasse, H., Maurer, G. FT-IR spectroscopic investigations of hydrogen bonding in alcohol-hydrocarbon solutions. Fluid Phase Equilibria, v. 186, p. 1-25, 2001

Jorgensen, W. L.; Maxwell, D. S.; Tirado-Rives, J., Development and Testing of the OPLS All-Atom Force Field on Conformational Energetics and Properties of Organic Liquids, J. Am. Chem. Soc., 118, 11225-11236 (1996).

Prausnitz, J. M., Lichtenthaler R. N., Azevedo, E. G. Molecular Thermodynamics of Fluid-Phase Equilibria

Voutsas, E., Perakis, C., Pappa, G., Tassios, D. An evaluation of the performance of the Cubic-Plus-Association equation of state in mixtures of non-polar, polar and associating compounds: Towards a single model for non-polymeric systems. Fluid Phase Equilibria, v.261, p. 343-350, 2007 